\title{
PERSPECTIVAS
}

Artigo convidado

Versão traduzida

DOI: http://dx.doi.org/10.1590/So034-759020200506

\section{FUTURO(S) DO TRABALHO}

Especulações sobre o futuro do trabalho são notoriamente escorregadias (Watson, 2008), variando desde narrativas tecnologicamente utópicas e progressistas (por exemplo, Handy, 1984) até previsões pessimistas sobre o fim do trabalho (por exemplo, Rifkin, 1995). No entanto, a impossibilidade de estabelecer empiricamente o que “poderia ser” (Watson, 2008) significa que uma boa dose de imaginação é necessária, tanto na formulação quanto na avaliação de tais especulações. Isso é particularmente verdadeiro em tempos socialmente turbulentos, que põem em questão a confiança relativa a inferências futuras a partir de tendências passadas. Em tais períodos - como o nosso -, o saber acadêmico sobre o ambiente do trabalho enfrenta um equilíbrio delicado: de um lado, as demandas para informar os debates públicos sobre o trabalho; de outro, as mudanças nas coordenadas socioeconômicas que recontextualizam esses debates. Os imaginários em torno dos futuros humanos diante da crise atuam simultaneamente como previsões e como gestos performativos (cf. Roux-Rosier, Azambuja, \& Islam, 2018), moldando ao mesmo tempo em que preveem, e mesclando responsabilidades científicas e políticas. A calma distância desfrutada pelos pesquisadores em tempos "normais" mostra-se apenas como a segurança dos privilegiados em manter a ilusão de normalidade. 0 que antes poderia ser justificado como consideração desinteressada sobre questões publicamente importantes aparenta ser, em momentos de crise, uma abdicação da responsabilidade social. Nesse sentido, escrever atualmente sobre o futuro do trabalho é construir eixos em torno dos quais esse futuro pode ser construído.

Em suma, o futuro do trabalho é hoje profundamente incerto, e tal incerteza deve ser reconhecida sem permitir que ela paralise a imaginação sociológica e despolitize a ação social. Sob certo ângulo, a epidemia da Covid-19 desafiou profundamente os modos de trabalho e organização (Grint, 2020; Kniffin et al., 2020). Além da pandemia, uma série crescente de crises ecológicas e climáticas abalará as bases da organização produtiva (Roux-Rosier et al., 2018). Nesse ínterim, prevê-se que as revoluções da inteligência artificial e do big data venham a alterar radicalmente a natureza e a existência do trabalho como o conhecemos (West, 2018). No entanto, sob outra perspectiva, alguns argumentam que essas crises simplesmente aprofundam e aceleram as tendências já existentes no ambiente do trabalho, de modo que, longe de permitir o surgimento de novos regimes de trabalho, podem simplesmente arraigar e consolidar os aspectos mais prejudiciais dos regimes de trabalho atuais (Kniffin et al., 2020).

No contexto dessa dupla perspectiva do status quo em relação tanto à ruptura quanto à

\section{GAZI ISLAM ${ }^{1,2}$}

gazi.islam@grenoble-em.com 0000-0002-6503-6018

${ }^{1}$ Grenoble Ecole de Management, Department of People, Organizations and Society, Grenoble, França

Institute for Research in Management and Economics, Annecy, França continuidade (ou ao entrelaçamento de ruptura e continuidade), minha intenção é refletir sobre o futuro, sem a pretensão de prever suas formas concretas. Para isso, enfocarei três campos nos quais creio que ocorrerão as lutas pelo futuro do trabalho. Eu as considero "lutas" porque seu resultado permanece indeterminado, mas as formas que assumem constituirão quais atividades compõem o “trabalho", quem estará envolvido nessas atividades e quem se beneficiará delas. Perpassando esses temas, estão as preocupações com o papel do trabalho em uma ordem social emergente e mais ampla. 


\section{As fronteiras do trabalho}

Um dos impactos mais frequentemente discutidos da pandemia da Covid-19 é a maneira como as fronteiras entre o trabalho nas diversas esferas sociais foram remodeladas por meio de respostas políticas (ou da falta delas) à pandemia (Cho, 2020). Por um lado, segmentos significativos de trabalho foram redefinidos como "teletrabalho", desde o trabalho burocrático de escritório e a telemedicina até a educação (Sewell \& Taskin, 2015). Essas realocações do trabalho para a casa (ou outros espaços conectados on-line) efetivamente converteram esses espaços em locais de produção econômica (formalmente reconhecida), trazendo consigo as várias normas e dinâmicas de poder que caracterizam as diferentes esferas sociais (Hatton, 2017). Ao mesmo tempo, trazer o escritório para dentro de casa implica trazer o espaço da casa para dentro do escritório, tornando possivel questionar as normas vigentes no local de trabalho, como a presença de crianças no trabalho, a formalidade do trabalho versus a conduta doméstica e as exigências de constante conexão versus o tempo de "desconexão" (cf. Morel, 2017). Essa indefinição da interface casa-trabalho também tornou visível o trabalho "oculto" de manter uma casa (por exemplo, Hatton, 2017), tornando mais difícil separar o trabalho remunerado do trabalho reprodutivo que tem permanecido amplamente fora da economia monetária (Fraser, 2014).

Afrouxar esses limites entre casa e trabalho oferece múltiplas possibilidades. A erosão do espaço entre a casa e o escritório pode assumir a forma de uma colonização daquela por este; nesse processo, o "mundo da vida" doméstico é convertido em um "sistema" racionalizado de produção econômica (Habermas, 1981). No entanto, esse afrouxamento também pode abrir espaços para a desracionalização, na medida em que o ambiente de trabalho ou o decoro profissional sejam relaxados como uma adaptação ao trabalho em casa. Se os sistemas de trabalho racionalizados exigirem a separação de um espaço de trabalho versus o espaço da "vida", a impossibilidade dessa separação pode forçar um ajuste entre essas esferas que carrega possibilidades emancipatórias no trabalho. É (talvez) mais provável que a racionalização se infiltre na própria casa, "taylorizando" a casa de modo a torná-la um espaço cada vez mais racionalizado, onde as atividades diárias são organizadas em torno da produtividade. Uma luta nessa interface parece inevitável, e sua resolução é uma questão de políticas em nível macro e de negociações em nível micro, ambas as quais ocorrerão em um contexto de assimetrias de poder cada vez maiores.

A onda de discussões a respeito do teletrabalho, entretanto, não deve obscurecer o fato de que essa transformação envolve diretamente um subconjunto muito limitado de trabalhadores. A maior parte do trabalho não se tornará, ainda, teletrabalho. Assim como o trabalho profissionalizado e de escritório adaptou-se ao ambiente on-line, uma vasta gama de trabalhadores da "linha de frente" permanece fisicamente exposta ao contágio e tem se adaptado a um cenário de trabalho modificado, sem a possibilidade de teletrabalho (Parks, Nugent, Fleischhacker, \& Yaroch , 2020). Embora a linha de frente frequentemente receba atenção e aplausos quando se trata de trabalhadores da área da saúde (o que não necessariamente se traduz em benefícios materiais para eles), trabalhadores precarizados em atividades de transporte, entregas, produção de alimentos, agricultura e outros setores de trabalho manual constituem uma "linha de frente invisível”. Em muitos casos, como na produção industrial de alimentos, esses trabalhadores convivem em espaços sob risco de infecção, e muitos pagam com suas vidas (Waltenberg, Victoroff, Rose et al., 2020). Além disso, em economias com grandes setores informais, pequenos comerciantes e outros empregos alternativos continuaram, em face da crise, com seus trabalhadores assumindo riscos semelhantes.

Em algumas dessas situações, como na produção industrial, os limites formais do trabalho se mantêm, mesmo enquanto a dinâmica do contágio transborda rapidamente do trabalho para a casa, à medida que parentes e colegas são expostos à doença. Para os trabalhadores informais e outros empregos na periferia da economia formal, a falta de proteção formal obriga os precarizados a escolher a exposição na ausência de opções econômicas. No primeiro caso, a falta de proteção aos trabalhadores levou à afirmação de limites de ambiente de trabalho contrários aos interesses dos trabalhadores. No segundo caso, a falta de limites deu aos trabalhadores a falta de abrigo seguro enquanto passam os dias buscando microrrendas em ruas vazias em meio a uma pandemia. Em alguns empregos, como os dos funcionários da Amazon, uma mistura das duas situações torna-se evidente.

Em terceiro lugar, à medida que os números do desemprego disparam a níveis sem precedentes em grande parte do mundo (Blustein et al., 2020; Coibion, Gorodnichenko, \& Weber, 2020), a fronteira entre trabalho e vida torna-se um muro que separa a vida sem recursos da possibilidade de sustento material. Apesar do fornecimento de auxílio na forma de várias assistências aos desempregados, variações significativas nos impactos entre as populações (Acs \& Karpman, 2020) provavelmente aumentarão a desigualdade; além disso, tais assistências podem ser insuficientes para sustentar as populações por longos períodos. A linha divisória entre produção e consumo, um mito formativo do trabalho moderno, é sustentável apenas na medida em que 
os ganhos da produção possam subsidiar as condições de vida necessárias. No contexto atual, é difícil imaginar como esse contrato tácito entre os mundos do trabalho e da vida possa ser sustentado.

Para ser claro, as questões de mediação tecnológica e teletrabalho, precariedade e falta de proteção ao trabalhador, juntamente com redes de proteção social inadequadas, não são exclusivas da época da Covid-19; na verdade, essas preocupações já existiam antes da pandemia. No entanto, o "teste de estresse" da Covid-19 acelerou seus efeitos, salientando seus contornos e trazendo essas questões de fronteiras centrais à discussão pública. O futuro do trabalho dependerá, em parte, de como essas fronteiras sejam mantidas, removidas ou remodeladas na esteira da crise.

\section{As solidariedades do trabalho}

Um corolário da discussão sobre os limites do trabalho é a questão da reconfiguração das comunidades em face das mudanças relacionadas ao trabalho. Afinal, mudar as fronteiras do trabalho é também mudar as categorias sociais definidas por essas fronteiras.

As discussões contemporâneas sobre o trabalho pósindustrial têm lutado com as dificuldades relativas às tradicionais concepções "proletárias” de trabalho, incluindo a luta social e política de classes ligada a essas concepções (Baldry et al., 2007; Gorz, 1982). Os desafios vêm de muitas perspectivas, em relação às mudanças na constituição da "classe trabalhadora". As primeiras discussões em torno do gerencialismo questionaram a relevância de uma classe gerencial ampliada para definir os trabalhadores. Por exemplo, os gerentes (enquanto empregados assalariados) devem ser pensados como trabalhadores ou são eles (enquanto agentes de controle dos trabalhadores) mais parecidos com os proprietários do capital (cf., Boltanski, 1982; Marks \& Baldry, 2009)? Fora das organizações, como já mencionado, um vasto segmento de trabalho oculto tem sido cada vez mais reconhecido como “moradas ocultas” da produção (Fraser, 2014), levando a definições ampliadas de trabalhador no sentido de incluir a produção de valor para além da organização, na "fábrica social” mais ampla (cf., Mumby, 2020). A crescente fragmentação das atividades laborais de produção em uma cadeia de valor global atomizada (Gereffi, 2005) e em formas não assalariadas de trabalho mascaradas como "contratos independentes", "gig jobs" ou "economia compartilhada” (Kalleberg \& Vallas, 2018; Petriglieri , Ashford, \& Wrzesniewski, 2019) tem dificultado cada vez mais a localização do ambiente do trabalho, à medida que ele se distribui por comunidades e regiões geográficas. Finalmente, o advento do trabalho digital e das redes sociais - nos quais a participação e a comunicação formam modelos de negócios baseados em dados que dependem dos conteúdos e cliques produzidos pelos usuários (Scholz, 2013) - significa que a própria conexão constitui um microtrabalho geralmente não remunerado, porém extremamente lucrativo para agregadores de dados como Google, Amazon ou Facebook.

Embora esses e outros desdobramentos no mundo do trabalho sejam distintos uns dos outros e possuam diferentes causas e efeitos, eles compartilham o aspecto comum de uma ampliação da categoria dos trabalhadores de modo a incluir comunidades de fora da classe trabalhadora tradicionalmente concebida como tal (Baldry et al., 2007). Esse desdobramento tem sido citado como parte de uma crise gradual da política trabalhista, uma crise em que as crescentes dispersão e pulverização da força de trabalho, bem como a falta de uma base comum em termos de geografia, cultura ou experiência compartilhada, criam desafios ao estabelecimento da solidariedade ou da ação política. De fato, discussões recentes sobre o trabalho precarizado têm destacado as dificuldades inerentes à organização entre diferentes públicos e tipos de trabalho, contratos individualizados, trabalho em meio período e tempo integral; estes constituem variações que dificultam a identificação de demandas comuns e a garantia de proteção aos trabalhadores (por exemplo, Gibson-Light, 2018). Além disso, tal pulverização torna mais fácil que diferentes grupos de trabalhadores considerem uns aos outros como irrelevantes ou concorrentes; assim colocados uns contra os outros, eles têm mais dificuldade de encontrar entre suas queixas particularizadas um conjunto abrangente de lutas comuns.

Por outro lado, a extensão (ou o reconhecimento) de aspectos econômicos em diversos tipos de atividades sociais cria possibilidades para formas ampliadas de solidariedade social que poderiam apoiar movimentos democráticos radicais. Em vez de representar uma classe trabalhadora no sentido estrito, a organização trabalhista contemporânea talvez precise se colocar nas interseções de classe, gênero, etnia e outros movimentos sociais, de modo a construir coalizões em torno de questões de justiça distintas, porém relacionadas (cf., Fraser, Bhattacharya, \& Arruzza, 2019). Fazer isso obriga os movimentos de trabalhadores a olhar além dos interesses de grupos restritos e a se concentrar em objetivos pluralistas e mudanças sociais de longo prazo. A ampliação para além de um horizonte imediato de articulação no nível da organização formal (embora isso continue taticamente importante) obriga os organizadores do trabalho a repolitizar o trabalho no sentido amplo de promover uma sociedade mais justa, em vez de visões estreitas da política de poder. 
Em suma, à medida que os aspectos economicamente produtivos da vida social se desvinculam do trabalho assalariado tradicional e se espalham entre o trabalho formal e o informal, a casa e o escritório, incluindo as próprias micropráticas de comunicação e participação, o que constitui um "trabalhador" muda. Não apenas os trabalhadores, mas os consumidores, prestadores de serviços, distribuidores e a categoria guarda-chuva dos "usuários" reconstituem as categorias nas quais a política pode ocorrer, exigindo novos discursos e práticas de solidariedade.

\section{As rendas do trabalho}

Relacionadas, mas distintas das questões dos limites e comunidades do trabalho, as questões do status econômico do trabalho e seu papel dentro do sistema socioeconômico mais amplo têm recebido atenção crescente (por exemplo, Dejours, Deranty, Renault, \& Smith, 2018; Pitts \& Dinerstein, 2017). Vários dos pontos supracitados - desde a criação de valor econômico a partir da "fábrica social" (ou seja, a esfera não remunerada) até a pulverização e distribuição do trabalho nas cadeias de valor globais - implicam um acoplamento um a um de criação de valor individual e remuneração parece cada vez mais impossível. $\mathrm{Na}$ verdade, esse acoplamento, vinculado à ideologia da meritocracia e do desempenho em nível individual, sempre foi um mito. No entanto, as reconfigurações descritas acima, somadas a uma mobilidade social reduzida (por exemplo, Milburn, 2016) e a choques sistêmicos, tais como pandemias, crises financeiras e a crise climática que se aproxima, provavelmente tornarão esses mitos cada vez mais insustentáveis.

Especificamente, conforme observado acima, a economia do "uso", na qual a produção de valor social por meio da participação, comunicação, socialização e outras atividades não remuneradas sustenta modelos de negócios de extração de renda, dissocia o trabalho da remuneração. Isso é mais óbvio em plataformas on-line (por exemplo, Scholz, 2013; Zuboff, 2019), onde a interação social é quantificada em dados que são comoditizados, geralmente sem remuneração: a maior parte da renda desse tipo de trabalho é obtida sem que os "trabalhadores" sequer saibam que estão trabalhando. Modos semelhantes de "prosumo" misturam acúmulo de renda em experiências de consumo social, em que os indivíduos trabalham de graça ou até pagam para produzir valor para as empresas. Embora esse trabalho não pago tenha sempre caracterizado as economias extrativistas do trabalho doméstico e outras economias informais, sua sistematização em arquiteturas globais de “compartilhamento" construiu uma enorme máquina que empreende a extração corporativa de valor social, totalmente dissociada da expectativa de um salário.

Em segundo lugar, a desintegração da produção que tem marcado as cadeias de valor globais (Gereffi, 2005) tem tornado cada vez mais difícil entender os componentes do valor em termos de insumos individuais, tornando impossível uma determinação justa do pagamento por trabalho em muitos casos. Mesmo quando cada etapa de uma cadeia de valor global é rastreada digitalmente, as contribuições relativas dos atores ao longo dessa cadeia têm pouco a ver com sua remuneração, que é determinada por suas posições estruturais na cadeia. A estrutura de subcontratação tipo dominó de certas cadeias de valor - como as relacionadas à construção civil e ao trabalho agrícola - deu origem a condições de trabalho que se aproximam ou constituem a escravidão moderna (Crane, 2012), com muitos se aproveitando e reforçando assimetrias de poder geopolítico, de modo a extrair valor das partes, dando-lhes, ao mesmo tempo, pouco ou nenhum poder de barganha. Nessas condições, a ligação entre o esforço e a remuneração do trabalhador é ilusória, e não fornece base para um contrato social entre os trabalhadores e a sociedade. Uma estrutura de incentivos capaz de fundamentar um contrato - ou seja, que os trabalhadores desenvolvem habilidades, aplicamnas para fins socialmente valiosos e são recompensados por seus esforços - torna-se cada vez mais afastada da realidade.

Finalmente, os eventos sistêmicos testemunhados durante a crise financeira de 2008, a pandemia de Covid-19 de 2020 e os prováveis eventos futuros relacionados aos choques climáticos e ambientais desmentem os sonhos neoliberais de uma vida sustentada pelo empreendimento e esforço individuais (Monbiot, 2016). Tais eventos derivam de atividades humanas em nível global e, portanto, requerem respostas globais (Fraser, 2008). Redes de segurança social (por exemplo, sistemas saúde, segurodesemprego e outros serviços públicos) oferecem amortecedores contra tais choques. Esses argumentos não são novos, mas, no contexto atual, eles assumem particular urgência: na conjuntura atual, as tentativas de manter um modelo competitivo de bemestar humano correm um risco malthusiano no qual o isolamento e a segurança de um pequeno grupo são comprados ao preço do sofrimento em massa. Essa fantasia distópica, sempre latente no pensamento liberal (Foster, 2000), foi capaz de coexistir com um verniz de "civilização" em períodos de crescimento sustentado; em momentos de dificuldade, no entanto, a civilização deve ser medida pelo quanto a sociedade protege seus membros mais vulneráveis.

Embora não exaustivos, esses três fenômenos - a saber, o surgimento de um trabalho como uso não remunerado em massa, a concentração de rendas e disseminação da precariedade por 
meio de cadeias de valor complexas e a exposição a choques globais recorrentes - sugerem, todos eles, o anacronismo da vinculação de compensação monetária à produção de valor social em nível individual. São necessárias alternativas a tais modelos, como algumas formas de renda básica universal e um maior investimento em bens públicos, além de outras formas de distribuição socialmente justa de valor. Essas alternativas podem libertar o trabalho de seus papéis mais coercitivos e permitir que ele assuma outras formas na produção de bens sociais.

\section{Resumindo}

Tomadas em conjunto, essas três questões distintas, mas relacionadas, em torno do trabalho - o estabelecimento de seus limites, as comunidades por ele constituídas e a distribuição de suas rendas - moldarão o futuro do trabalho. Em cada uma das grandes áreas, vários temas aparecem em vários lugares, incluindo a fronteira tensa entre a casa e o escritório/fábrica, a crescente precarização e sua relação com o trabalho tradicional, e a possibilidade de grandes turbulências envolvendo forças sociais e naturais que tornam instável e provisória qualquer relação de trabalho.

Permeando os temas gerais, está o sentido de uma avaliação dual, embora assimétrica, das consequências emancipatórias versus opressivas de cada tema. A quebra da fronteira entre casa e trabalho ocorrerá (muito provavelmente) às custas do espaço seguro da casa, em vez da dominação racionalizada do trabalho. No entanto, a mesma abertura oferece uma oportunidade para o próprio trabalho ser modificado pela crescente mistura com espaços mais humanos de valor social vivenciado. A extensão das plataformas digitais e soluções de “compartilhamento" muito provavelmente está relacionada à aceleração do capitalismo de vigilância (Zuboff, 2019) e sua comodificação de tudo baseada em dados. Entretanto, ela também abre novos terrenos de contestação nos quais persistem possibilidades democráticas. Embora as vozes esperançosas da democracia digital, tão ativas durante a chamada Primavera Árabe (Boros \& Glass, 2014), tenham sido logo suplantadas pelo horror visto em suas consequências, continuam em aberto os potenciais democráticos das plataformas das mídias sociais, se dissociadas de seus hospedeiros corporativos (Scholz \& Schneider, 2016). Embora os choques de crises financeiras e pandemias provavelmente venham a dar origem a novas formas de controle e dificuldades econômicas, eles também podem abrir espaços para mudanças profundas no "business as usual".
Essas probabilidades não são, ocioso dizer, baseadas em análises empíricas - e, mesmo que fossem, estas seriam difíceis de justificar em meio a tempos incertos, quando acreditar que o futuro se parecerá com o passado não é mais do que um artigo de fé. Então, de onde elas vêm? Minha resposta é que pensar sobre o futuro do trabalho em meio à pandemia da Covid-19 requer o sóbrio senso de uma estrada difícil e entrecortada de mato uma estrada que não é um beco sem saída, mas sim um caminho em construção. Nossas formas passadas de traçar caminhos acabaram provocando destruição, mas as pessoas no futuro devem permanecer esperançosas (embora cautelosas) em relação a narrativas excessivamente progressistas ou visões majestosas da humanidade. Onde até hoje o trabalho foi considerado uma “saída”, ele agora deve se tornar um caminho de volta para dentro. Embora possa não ser reconhecível como tal, existe e continuará a existir trabalho a ser feito.

\section{REFERÊNCIAS}

Acs, G., \& Karpman, M. (2020). Employment, income, and unemployment insurance during the Covid-19 Pandemic. Washington, USA: Urban Institute.

Baldry, C., Bain, P., Taylor, P., Human, J., Scholarios, D., Marks, A., ... Bunzel, D. (2007) The meaning of work in the new economy. New York, USA: Palgrave Macmillan.

Blustein, D. L., Duffy, R., Ferreira, J. A., Cohen-Scali, V., Cinamon, R. G., \& Allan, B. A. (2020). Unemployment in the time of Covid-19: A research agenda. Journal of Vocational Behavior, onlinefirst.

Boltanski, L. (1982). Les cadres: La formation d'un groupe social. Paris, France: Minuit.

Boros, D., \& Glass, J. M. (2014). Introduction. In D. Boros, \& J. M. Glass (Eds.), Re-imagining public space: The Frankfurt School in the 21st Century (pp. 1-18). New York, USA: Palgrave Macmillan.

Cho, E. (2020). Examining boundaries to understand the impact of Covid-19 on vocational behaviors. Journal of Vocational Behavior, onlinefirst.

Coibion, O., Gorodnichenko, Y., \& Weber, M. (2020). Labor markets during the Covid-19 crisis: A Preliminary [NBER Working Paper $\mathrm{n}$. 27017].

Crane, A. (2012). Modern slavery as a management practice: Exploring the conditions and capabilities for human exploitation. Academy of Management Review, 31(1), 49-69. doi: 10.5465/amr.2011.0145

Dejours, C., Deranty, J. P., Renault, E., \& Smith, N., (2018). The return of work in critical theory. New York, USA: Columbia University Press.

Foster, J. B. (2000) Marx's ecology: Materialism and nature. New York, USA: Monthly Review Press.

Fraser, N. (2008). Scales of justice: Reimagining political space in a globalised world. Cambridge, UK: Polity Press. 
Fraser, N. (2014) Behind Marx's hidden abode: For an expanded conception of capitalism. New Left Review, 86, 55-72.

Fraser, N., Bhattacharya, T., \& Arruzza, C. (2019). Feminism for 99\%: A manifesto. London, UK: Verso.

Gereffi, G. (2005) The global economy: Organization, governance and development. In N. Smelser, \& R. Swedberg (Eds.), Handbook of economic sociology (pp. 160-182). Princeton, USA: Princeton University Press.

Gibson-Light, M. (2018). Classificaiton struggles in semi-formal and precarious work: Lessons from inmate labor and cultural production. Research in the Sociology of Work, (31), 61-89. doi: 10.1108/So277283320170000031002

Gorz, A. (1982) Farewell to the working class. Boston, USA: South End Press.

Grint, K. (2020). Leadership, management and command in the time of the Coronavirus. Leadership, 16(3), 314-319. doi: $10.1177 / 1742715020922445$

Habermas, J. (1981). The theory of communicative action, vols. 1 and 2 (T. McCarthy, Trans.). Boston: Beacon Press.

Handy, C. (1984) The future of work. Oxford, UK: Basil Blackwell.

Hatton, E. (2017). Mechanisms of invisibility: Rethinking the concept of invisible work. Work, Employment and Society, 31(2), 336-351. doi: 10.1177/0950017016674894

Kalleberg, A. L., \& Vallas, S. P. (2018). Probing precarious work: Theory, research, and politics. Research in the Sociology of Work, 31, 1-30. doi: $10.1108 /$ So277-283320170000031017

Kniffin, K. M., Narayanan, J., Anseel, F., Antonakis, J., Ashford, S., Bakker, A. B., ... Vugt, M. Van. (2020, June 15). Covid-19 and the workplace: Implications, issues, and insights for future research and action. Retrived from https://hbswk.hbs.edu/item/covid-19-andthe-workplace-implications-issues-and-insights-for-future-researchand-action

Marks, A., \& Baldry, C. (2009). Stuck in the middle with who? The class identity of knowledge workers. Work, Employment \& Society, 23(1), 49-65. doi: 10.1177/0950017008099777

Milburn, A. (2016). The social mobility index. Retrieved from https:// www.gov.uk/government/uploads/system/uploads/attachment_ data/file/496103/Social_Mobility_Index.pdf

Monbiot, G. (2016). How did we get into this mess? Politics, equality, nature. London, UK: Verso Books.
Morel, L. (2017). Le droit à la déconnexion en droit français : La question de l'effectivité du droit aurepos à l'ère du numérique. Labor \& Law Issues, 3(2), 1-16. doi: 10.6092/issn.2421-2695/7570

Mumby, D. K. (2020). Theorizing struggle in the social factory. Organization Theory, 1(2), onlinefirst.

Parks, C. A., Nugent, N. B., Fleischhacker, S. E., \& Yaroch, A. L. (2020). Food system workers are the unexpected but under protected Covid heroes. The Journal of Nutrition, onlinefirst.

Petriglieri, G., Ashford, S. J., \& Wrzesniewski, A. (2019). Agony and ecstasy in the gig economy: Cultivating holding environments for precarious and personalized work identities. Administrative Science Quarterly, 64(1), 124-170. doi: 10.1177/0001839218759646

Pitts, F. H., \& Dinerstein, A. C. (2017). Postcapitalism, basic income and the end of work: $A$ critique and alternative [Bath Papers in International Development and Wellbeing No. 55]. University of Bath, UK.

Rifkin, J. (1995) The end of work: The decline of the global labour force and the dawn of the post-market era. New York, USA: Putnam.

Roux-Rosier, A., Azambuja, R., \& Islam, G. (2018). Alternative visions: Permaculture as imaginaries of the Anthropocene. Organization, 25(4), 550-572. doi: 10.1177/1350508418778647

Scholz, T. (Ed.). (2013). Digital labor: The internet as playground and factory. New York, USA: Routledge.

Scholz, T., \& Schneider, N. (2016) Ours to hack and to own: The rise of platform cooperativism, a new vision for the future of work and a fairer internet. New York, USA: OR books.

Sewell, G., \& Taskin, L. (2015). Out of sight, out of mind in a new world of work? Autonomy, control, and spatiotemporal scaling in telework. Organization Studies, 36(11), 1507-1529. doi: $10.1177 / 0170840615593587$

Waltenburg, M. A., Victoroff, T., Rose, C. E. et al. (2020). Covid-19 response team. Update: Covid-19 among workers in meat and poultry processing facilities - United States, April-May 2020. MMWR Morb. Mortal.Wkly.Rep.2020, 69, 887-892.

Watson, T. J. (2008). Sociology, work and industry (5th ed.). London, UK: Routledge.

West, D. M. (2018) The future of work: Robots, Al, and automation. Washington, USA: Brookings Institution Press.

Zuboff, S. (2019). The age of surveillance capitalism: The fight for a human future at the new frontier of power. London, UK: Profile Books.

\section{CONTRIBUIÇÃO DO AUTOR}

O autor declara que participou de todas as fases do desenvolvimento do manuscrito. Desde a conceitualização e abordagem teórico-metodológica, revisão teórica (pesquisa da literatura), e finalmente, a escrita e revisão final do artigo. 